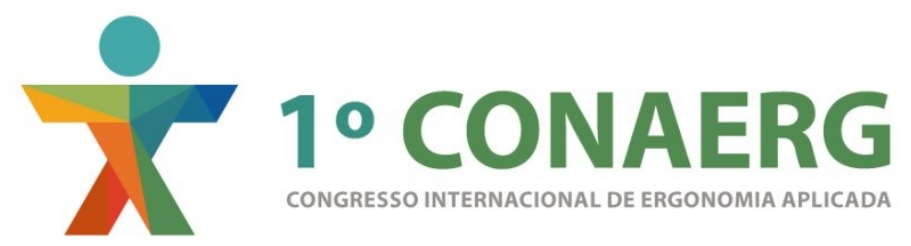

\title{
ANÁLISE DA USABILIDADE DA HOMEPAGE DA APPLE BRASIL
}

\author{
Simone Jacqueline Portela Simão (1); \\ Marilande Andrade (2); \\ Marcelo Gomes (3); \\ Alaíde Farias de Almeida Filha (4); \\ Marcelo Márcio Soares (5)
}

Universidade Federal de Pernambuco,

(1) (2) (3) (4) Mestrandos em Ergonomia

(1) e-mail: simone jacqueline@yahoo.com.br

(2) e-mail: marilande andrade@hotmail.com

(3) e-mail: marceloh2@yahoo.com.br

(4) e-mail: alaideff@hotmail.com

(5) PhD em Ergonomia

e-mail: soaresmm@gmail.com

\begin{abstract}
RESUMO
O presente artigo refere-se a um estudo de usabilidade na Homepage da Apple Brasil, Foram aplicados questionários para avaliar o grau de satisfação dos usuários com a web estudada. Para fundamentar este estudo utilizamos a avaliação Heurística segundo os critérios de Nielsen (1993) e o modelo de Leventhal e Barnes (2008). Ao final do artigo são apresentados os resultados obtidos com a pesquisa bem como algumas sugestões de melhorias.
\end{abstract}

Palavras-chave: Usabilidade, Interface, Interação Humano-Computador e Ergonomia

\begin{abstract}
This article refers to a usability study in the homepage of Apple Brazil, questionnaires were used to assess the degree of user satisfaction with the studied web. To support this study we use the Heuristic evaluation according to the criteria Nielsen (1993) and the model of Leventhal and Barnes (2008). At the end of the article presents the results obtained from the research as well as some suggestions for improvements.
\end{abstract}

Keywords: Usability, Interface, Human-Computer Interaction and Ergonomics 
O surgimento da internet teve muita influência em nossa sociedade, Além de facilitar a interação entre as pessoas, mudou a maneira de se adquirir informação, conhecimento e ainda ampliou os domínios dos negócios, pois possibilitou o surgimento de um novo meio de comercialização chamado comércio eletrônico (e-commerce), caracterizado pela compra e venda através da internet com uso de um dispositivo digital.

Com isso as empresas iniciaram a utilizar recursos de tecnologia da informação na busca por maior produtividade e melhoria nos serviços oferecidos a seus clientes. Deste modo o acesso à informação de qualidade é essencial para a eficácia de uma organização (FERREIRA; NUNES, 2008).

Com o surgimento desta "nova forma" de negócio a web vem sendo considerada como um meio eficiente de divulgar e vender produtos e serviços o que contribuiu para o aumento dos projetos de construções de homepages voltadas para comercialização dos mais diversos tipos de mercadorias. O que contribuiu para o aumento da necessidade por interfaces eficientes na tentativa de melhorar a interação com o cliente.

Atualmente as empresas investem milhões de dólares em suas homepages na tentativa de atrair e fidelizar novos clientes. Em sites na web, o processo de fidelizar clientes é ainda mais complicado, pois a ação de trocar pelo concorrente é muito simples e depende apenas de um clique no mouse.

Segundo Ferreira e Nunes (2008), os usuários acessam um site porque "o encontram disponível, mas só retornam se veem nele algum valor, bem como facilidade de operação", ou seja, que ele promova uma boa interação humano-computador (IHC). Isto é, deve favorecer uma boa relação entre os seus usuários e máquinas.

Neste sentido, Veldof, Prasse e Mills (1999) apontam os testes de usabilidade como sendo uma ótima forma de se entender o que os usuários querem e de que precisam para realização de suas tarefas. Assim sendo usabilidade tem a ver com cativar usuários oferecendo-lhes um website de navegação agradável, rápida e eficiente, com o objetivo de ganhos de negócios.

Diante dos fatores acima expostos a proposta de estudo foi iniciar uma avaliação de usabilidade da homepage da Apple Brasil (http://www.apple.com/br/) através de métodos de avaliação de software.

A Apple foi fundada por Steve Wozniak e Steve Jobs com o nome de Apple Computers, em 1974. Sediada em Cupertino, na Califórnia, desenvolve, vende e oferece suporte a uma série de computadores pessoais, reprodutores de mídia portáteis, software e hardware. Entre os produtos mais conhecidos da empresa estão a linha de computadores Mac, seu sistema operacional Mac OS X e a linha iPod de reprodutores de mídia portáteis. Para 0 iPod e seu programa, o itunes, a Apple vende audio books, filmes, jogos, música, programas televisivos e videoclipes na sua iTunes Store, recentemente entrou no ramo de celulares com a criação do iPhone.

Para análise da homepage, avaliamos a usabilidade utilizando os princípios de design de interação, diretrizes gerais para o design e diretrizes para o design visual de Leventhal e Barnes, 2008.

Na segunda etapa para verificar a interação do usuário com o site, foram feitas observações e foi aplicado um questionário com perguntas abertas e fechadas, para avaliar o grau de satisfação de Usuários com a homepage estudada. 
$\mathrm{Na}$ etapa final foram feitas recomendações e uma proposta de solução de melhoria relacionadas a causa do problema levantado durante a pesquisa e a partir da demanda dos usuários.

\subsection{Usabilidade e interfaces de sistemas}

A Ergonomia, enquanto disciplina científica, objetiva adequar os sistemas e os ambientes de trabalho ao homem. Moraes e Mont'alvão (2000) entendem a ergonomia como facilitadora da aproximação entre homem e tecnologia, fornecendo técnicas e subsídios para adaptar o trabalho ao ser humano.

Hoje se sabe que a qualidade do desempenho do usuário está ligada à qualidade de sua interface com o sistema. Assim,

O desenvolvimento de sistemas interativos de qualidade exige a utilização conjunta e integrada de conceitos e técnicas específicas do domínio conhecido como Interação Humano-Computador (IHC) e de conceitos e métodos de desenvolvimento de sistemas considerados integrantes do domínio da Engenharia de Software. (CYBIS at al, 1999)

Para Maddix, 1990 (apud BARROS, 2003), interface pode ser conceituada como parte do sistema com o qual o usuário realiza contato através do plano físico, perceptivo e cognitivo.

Segundo Pressman (1995), todos os usuários já se depararam com alguma interface confusa ou até mesmo frustrante. A interface é vista como a embalagem do software, assim, ela deve conter certas características como: facilidade de aprendizagem, simplicidade de uso, emitir clareza. Caso a interface não possua esses itens, certamente ocorrerão problemas.

Como o diálogo entre a máquina e o homem se dá através da interface, e se os fatores humanos tiverem sido levados em conta, o diálogo será harmonioso e um ritmo será estabelecido entre o usuário e o programa. Se os fatores humanos tiverem sido ignorados, o sistema, quase sempre, será visto como "não amigável" (PRESSMAN, 1995).

De acordo com Prates (2003), a interface é toda porção de um sistema com a qual o usuário mantém contato ao utilizá-lo.

Assim sendo, o objetivo de avaliar o efeito da interface junto ao usuário, que significa avaliar sua usabilidade, visa considerar aspectos, tais como: avaliar quão fácil é aprender a utilizar o sistema e identificar áreas do design que sobrecarregam o usuário, de alguma maneira. (BARROS, 2003)

Para Moraes (2002), a usabilidade é parte da metodologia ergonômica de adequações das interfaces às características e às capacidades humanas físicas, cognitivas e emocionais. Portanto, deve ser item de preocupação para os desenvolvedores, já que podem influenciar diretamente no bem-estar dos usuários ao realizarem quaisquer tarefas no produto desenvolvido.

Segundo Cybis, 2010, a usabilidade é a qualidade que caracteriza o uso dos programas e aplicações.

Nielsen (1993) a conceitua como um atributo de qualidade que avalia o quão fácil é a interface do sistema. A avaliação de usabilidade segundo ele seria um nome genérico para 
um grupo de métodos baseados na avaliação e inspeção ou exame relacionado com aspectos de usabilidade da interface com o usuário.

Assim, os processos de avaliação que incorporam o fator humano como elemento fundamental terão prováveis oportunidades de descobrir novas situações até então não previstas. A Usabilidade não pode ser analisada de forma isolada, pois depende da interação entre o sistema, o usuário, a tarefa e o ambiente em que está inserido.

\section{PROCEDIMENTOS METODOLÓGICOS}

O presente trabalho para avaliar a usabilidade da homepage da Apple Brasil fez uso de uma pesquisa de cunho exploratório descritiva quanti-qualitativa.

Segundo Leite (2007), a avaliação de usabilidade pode ser realizada levando em consideração diferentes métodos, que podem ser definidos de acordo com o objetivo da avaliação.

De acordo com Leventhal \& Barnes (2008), um modelo não apenas estabelece as características de uma interface utilizável, mas também indica como essas características se encaixam, o que significam e como contribuem para a usabilidade. Sem um modelo e suas implicações sobre o efeito causal de diferentes interfaces de usuários e as características situacionais, possivelmente o engenheiro/designer de usabilidade teria que adivinhar os fatores que influenciam potencialmente na usabilidade (Apud FALCÃO E SOARES, 2013).

Sendo assim, na etapa inicial analisamos a usabilidade utilizando os princípios de design de interação, diretrizes gerais para o design e diretrizes para o design visual de Leventhal e Barnes, 2008.

\subsection{Modelo de Avaliação de usabilidade proposto por Leventhal e Barnes (2008)}

Leventhal e Barnes (2008), propuseram um modelo para avaliação de usabilidade baseado em modelos desenvolvidos por Shackel (1991), Nielsen (1993), e Eason (1984) para a análise de usabilidade em softwares e websites, a partir do contexto da interação humanocomputador.

Segundo Falcão e Soares (2013), o modelo proposto é uma tentativa de colocar juntos os fatores mais importantes dos três modelos que foram considerados, e assume que um número de variáveis que são tomadas juntas determinará se a interface tem boa usabilidade. Tais variáveis dividem-se em: variáveis situacionais e variáveis de interface do usuário, conforme ilustrado na figura 1.

Figura 1 - Modelo de usabilidade proposto por Leventhal \& Barnes (2008. P 36).

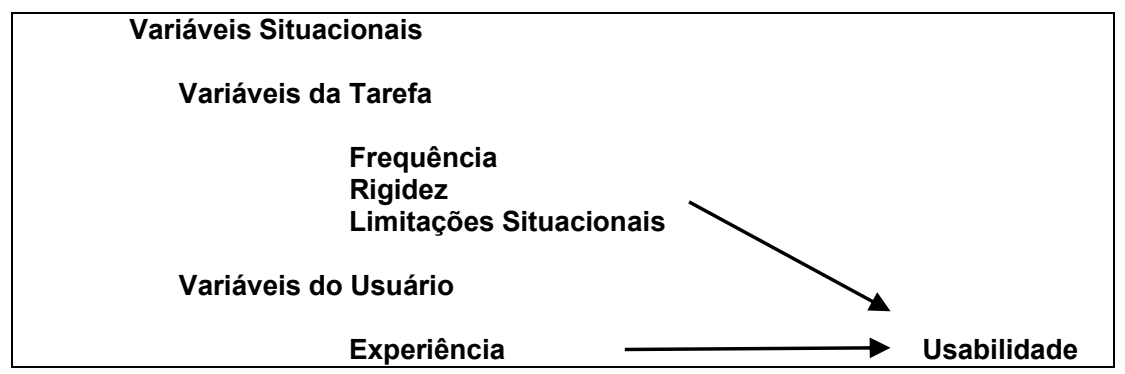




\begin{tabular}{|l|}
\hline Motivação \\
Variáveis de Interface do Usuário \\
Facilidade de aprender \\
Facilidade de usar \\
Facilidade de reaprender \\
Flexibilidade \\
Satisfação \\
Correspondência da tarefa \\
\hline
\end{tabular}

\section{ANÁLISE DA PAGINA WEB DA APPLE BRASIL}

\subsection{Análise da Página web da Apple Brasil Considerando as Recomendações para o Design de Interação}

A homepage da Apple Brasil foi analisada em relação ao design de interação que se preocupa com usabilidade da interface e as interações individuais. Nesta etapa foi observado como o usuário interage com a homepage sob a ótica dos pesquisadores.

A homepage estudada usa manipulação de estilos de Interação Multimídia. Apresenta informações de diversas formas, incluindo texto, imagens gráficas, áudio, vídeo e janela de bate-papo para auxiliar o usuário na navegação no site e na compra do produto.

As funções e a maneira de acioná-las estão visíveis na forma de opções para o usuário selecionar. Existe uma demanda maior pelo processo de reconhecimento de imagens e caracteres ao invés de interfaces baseadas em comandos. Apresenta um conjunto de ícones que representam as opções, como um menu com barras. A Plataforma não apresenta constrangimentos ao usuário e também apresenta aparência padronizada no site, como mostrado na figura 2 .

Na Página da Apple as imagens de background são alteradas automaticamente, de maneira a apresentar os diversos produtos da empresa.

Figura 2 - Imagem inicial da Homepage Apple Brasil.

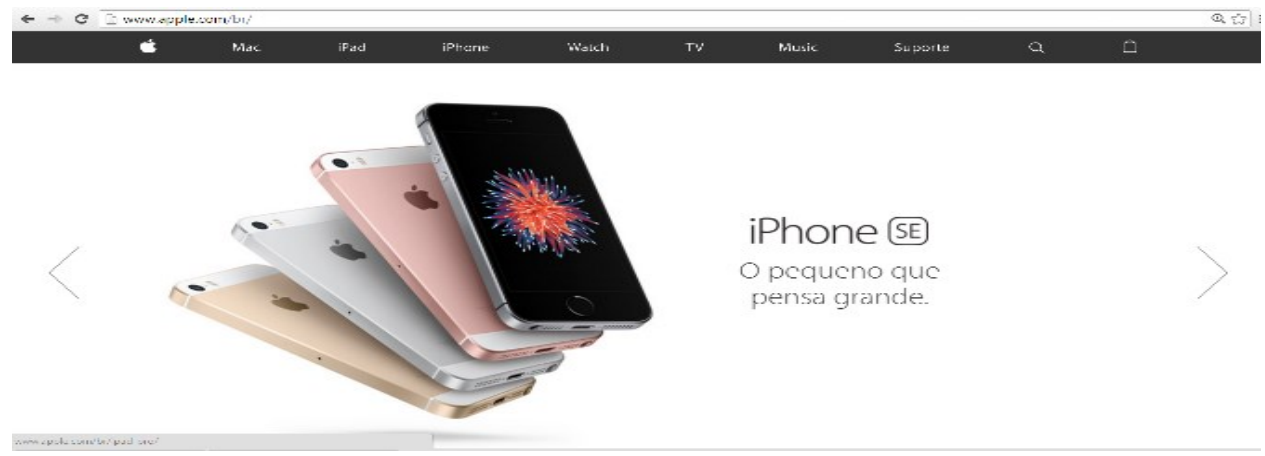

Nas interfaces textuais (ou baseadas em caracteres) as opções são descritas através de palavras na linguagem do usuário que representem as funções do sistema correspondentes 
aos comandos. O comando é acionado através de um clique no mouse, como mostrado na figura 3.

Figura 3 - Imagem final da Homepage Apple Brasil.

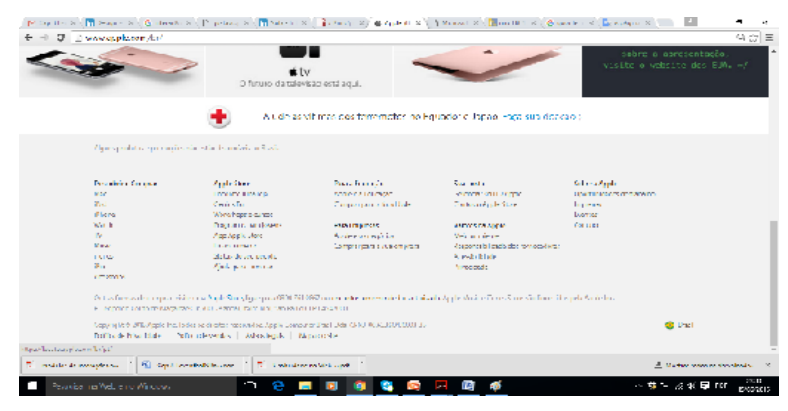

Na Página específica do Produto: existe uma combinação entre palavras e imagens que auxiliam o usuário na navegação no site. Onde a empresa apresenta todos os produtos oferecidos para venda. O Usuário também tem acesso a todas as informações do produto com facilidade, como observado na figura 4.

Figura 4 - Imagem da Homepage especifica de produto.

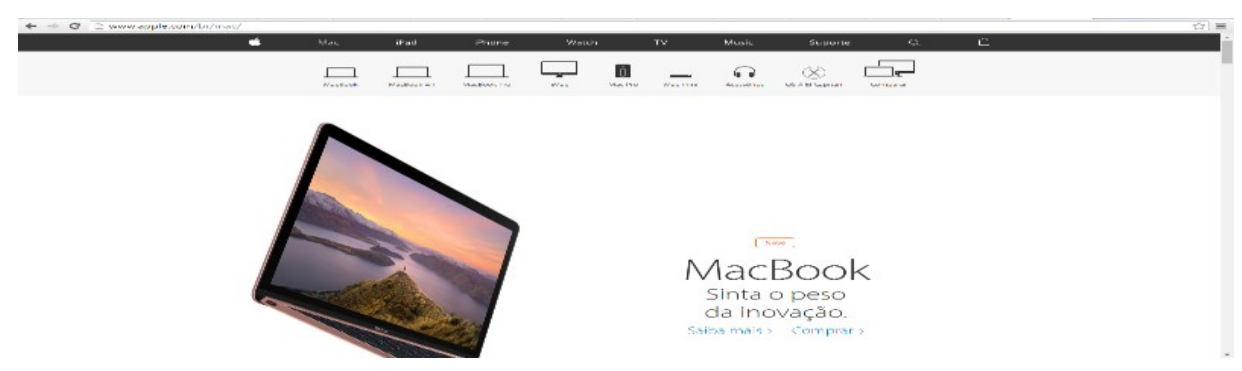

O usuário tem ainda a opção de clicar em Ajuda para Comprar. Bate papo ao vivo. Onde aparece uma janela de bate papo on line onde um especialista em vendas o auxilia na escolha do produto e compra. A janela de conversação apresenta cor de fundo branca e ainda são diferenciados os espaços onde aparecem a escrita do usuário (em cinza) e a cor do atendente (em azul). Como podemos visualizar na figura 5.

Figura 5 - Imagem do chat disponibilizado no site. 


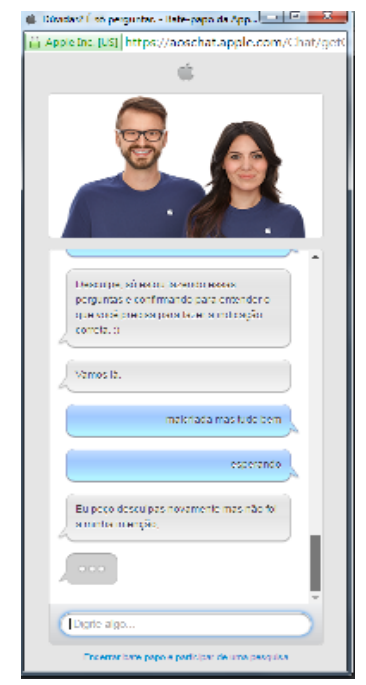

Os vídeos apresentados no site funcionam da maneira esperada. Tem excelente qualidade de imagem e som. Carregam rapidamente. O único problema encontrado foi que o áudio do vídeo é em inglês.

O site somente requisita preenchimento de formulário em caso de efetivação de compra e foi considerado satisfatório pelos usuários.

O site da Apple Brasil atende as seguintes diretrizes gerais do design:

- Utiliza modelos mentais semelhantes ao funcionamento de outros sites e as ações se apresentam de forma consistente.

- Apresenta ícones de fácil identificação as tarefas e produtos. Os ícones utilizados são apropriados as tarefas dos usuários.

- Não há figuras que atrapalhem a atenção do usuário em relação à tarefa.

- As principais informações estão em destaque reduzindo assim a sobrecarga cognitiva do usuário. Informações como suporte ao produto, dos produtos, pesquisa, compra etc..

- Nenhuma ação que ocorre no site é realizada a revelia do usuário ele comanda todas as ações do site.

- Os vídeos apresentados no site funcionam da maneira esperada.

- Os textos apresentado no site são claros e objetivos.

- Os links funcionam da maneira esperada.

\subsection{Análise da Homepage da Apple Brasil segundo as recomendações para o Design Visual}

- Uso da Cor e Contraste dos planos frente e fundo - A Apple usa fundo branco e cinza, e letras basicamente em preto e azul e em alguns lugares onde o fundo é 
preto usa imagens e letras em cores brancas. Fazendo o contraste para distinção de cores. E ainda usa algumas cores neutras para letras. Isso facilita a utilização do site por pessoas que apresentam deficiência com cores como os daltônicos.

- Uso de Fontes - Usa fonte de mais de um estilo, tamanho e cor. Usado assim para chamar atenção e marcar a importância do ponto abordado.

- Uso de Símbolos - Os ícones utilizados são apropriados as tarefas dos usuários apresenta ícones de fácil identificação as tarefas do usuários e produtos. Não há figuras que atrapalhem a atenção do usuário em relação a tarefa. Não causando sobrecarga cognitiva ao usuário.

\section{ESTUDO DE CAMPO - PONTO DE VISTA DO USUÁRIO}

Para a análise da avaliação da homepage estudada sob o ponto de vista do usuário fizemos uso de entrevistas informais e aplicamos um questionário com perguntas abertas e fechadas. Este estudo teve como objetivo avaliar o comportamento do usuário em relação: 1) A sua experiência de navegação no site e os aspectos visuais opinião dos usuários; 2) A procura de produtos; 3) Processo de Compra e 4) Serviços prestados aos clientes, confiança e credibilidade.

\subsection{Perfil do usuário}

A entrevista foi feita com 8 (oito) usuários sendo: 4 (quatro) do sexo feminino e 4 (quatro) do sexo masculino com idades entre 21 e 37 anos. Quanto a escolaridade apenas um dos entrevistados faz curso técnico, os demais são um administrador, quatro estudantes de graduação em: administração, sistema de informação, secretariado e enfermagem; um é estudante de curso de especialização em direito tributário e um estudante de doutorado em do curso de educação. Todos os usuários que participaram do estudo tinham experiência de: mais de um ano de uso de computador, mais de três anos de navegação na internet. Mas apesar disso apenas um já havia feito compras no site avaliado. Isso pode ser melhor visualizado na figura 6 .

Figura 6 - Quadro de Perfil dos usuários.

\section{Quadro de Perfil dos Usuários}

\begin{tabular}{|c|c|c|c|c|c|c|c|c|}
\hline Perguntas & $\begin{array}{l}\text { Usuário } \\
\text { (1) }\end{array}$ & Usuário (2) & Usuário (3) & Usuário (4) & $\begin{array}{c}\text { Usuário } \\
\text { (5) }\end{array}$ & $\begin{array}{c}\text { Usuário } \\
\text { (6) }\end{array}$ & $\begin{array}{l}\text { Usuário } \\
\text { (7) }\end{array}$ & $\begin{array}{l}\text { Usuário } \\
\text { (8) }\end{array}$ \\
\hline Idade & 28 & 23 & 30 & 26 & 26 & 21 & 37 & 31 \\
\hline Sexo & $M$ & $\mathrm{M}$ & $F$ & $\mathrm{~F}$ & $\mathrm{~F}$ & $M$ & $M$ & $\mathrm{~F}$ \\
\hline $\begin{array}{l}\text { Profissão e } \\
\text { escolaridade }\end{array}$ & $\begin{array}{c}\text { Servidor } \\
\text { Publico } \\
\text { Estudante } \\
\text { PG em } \\
\text { Direito }\end{array}$ & $\begin{array}{l}\text { Estudante de } \\
\text { Administração }\end{array}$ & Administradora & $\begin{array}{c}\text { Estudante } \\
\text { de } \\
\text { Secretariado }\end{array}$ & $\begin{array}{c}\text { Estudante } \\
\text { curso } \\
\text { técnico }\end{array}$ & $\begin{array}{l}\text { Estudante } \\
\text { Sistema de } \\
\text { Informação }\end{array}$ & $\begin{array}{c}\text { Técnicos } \\
\text { em } \\
\text { assuntos } \\
\text { educ. } \\
\text { Estudante } \\
\text { Do }\end{array}$ & $\begin{array}{c}\text { Estudante } \\
\text { de } \\
\text { Serviço } \\
\text { Social }\end{array}$ \\
\hline $\begin{array}{l}\text { Há quanto tempo que } \\
\text { utiliza computador? }\end{array}$ & $\begin{array}{c}\text { Entre } 1 \text { e } \\
2 \text { anos }\end{array}$ & + de 5 aa & $\begin{array}{l}\text { Entre } 1 \text { e } 2 \\
\text { anos }\end{array}$ & + de 5 aa & $\begin{array}{l}\text { Entre } 1 \text { e } \\
2 \text { anos }\end{array}$ & + de 5 aa & + de 5 aa & + de 5 aa \\
\hline $\begin{array}{l}\text { Quantas horas utiliza } \\
\text { computador por }\end{array}$ & + de $10 \mathrm{~h}$ & + de $10 \mathrm{~h}$ & + de $10 \mathrm{~h}$ & + de $10 \mathrm{~h}$ & - de $2 h$ & + de $10 \mathrm{~h}$ & + de $10 \mathrm{~h}$ & Entre $2 \mathrm{e}$ \\
\hline
\end{tabular}




\begin{tabular}{|c|c|c|c|c|c|c|c|c|}
\hline semana? & & & & & & & & $5 \mathrm{~h}$ \\
\hline $\begin{array}{l}\text { Há quanto tempo } \\
\text { Navega na internet? }\end{array}$ & $\begin{array}{l}3 \text { aa ou } \\
\text { mais }\end{array}$ & 3 aa ou mais & 3 aa ou mais & $\begin{array}{c}3 \text { aa ou } \\
\text { mais }\end{array}$ & $\begin{array}{c}3 \text { aa ou } \\
\text { mais }\end{array}$ & $\begin{array}{c}3 \text { aa ou } \\
\text { mais }\end{array}$ & $\begin{array}{c}3 \text { aa ou } \\
\text { mais }\end{array}$ & $\begin{array}{c}3 \text { aa ou } \\
\text { mais }\end{array}$ \\
\hline $\begin{array}{l}\text { Quanto tempo fica } \\
\text { conectado por } \\
\text { semana? }\end{array}$ & + de $10 \mathrm{~h}$ & + de $10 \mathrm{~h}$ & + de $10 \mathrm{~h}$ & + de $10 h$ & + de 3aa & + de $10 \mathrm{~h}$ & + de $10 \mathrm{~h}$ & + de $10 \mathrm{~h}$ \\
\hline $\begin{array}{l}\text { Quanto tempo você fica } \\
\text { conectado em sites de } \\
\text { compras por semana? }\end{array}$ & - de $1 \mathrm{~h}$ & - de $1 \mathrm{~h}$ & - de $1 \mathrm{~h}$ & + de1h & + de $1 \mathrm{~h}$ & - de1h & - de $1 \mathrm{~h}$ & - de $1 \mathrm{~h}$ \\
\hline $\begin{array}{l}\text { Quantas vezes você já } \\
\text { visitou o site da Apple? }\end{array}$ & 1 & 1 & 1 & $\begin{array}{c}+ \text { de } 20 \\
\text { vezes }\end{array}$ & 1 & 1 & 1 & 1 \\
\hline
\end{tabular}

\subsection{Análise dos dados}

\subsubsection{Experiência da navegação no site}

Quando os usuários foram solicitados a responder sobre suas experiências de navegação no site: oito concordaram que o site é de apresentação gráfica agradável, legível e claro em seus objetivos; sete que é de fácil navegação e que apresenta clareza textual; Seis sabiam aonde estavam e aonde iriam e, que o site é rápido; cinco que os recursos do site são claros e que os títulos das páginas eram muito intuitivos. Porém apenas dois disseram que já sabiam aonde os levariam os links antes de clicá-los. Como pode ser observado na figura 7.

Figura 7 - Opinião dos usuários com relação a sua experiência de Navegação no site da Apple.

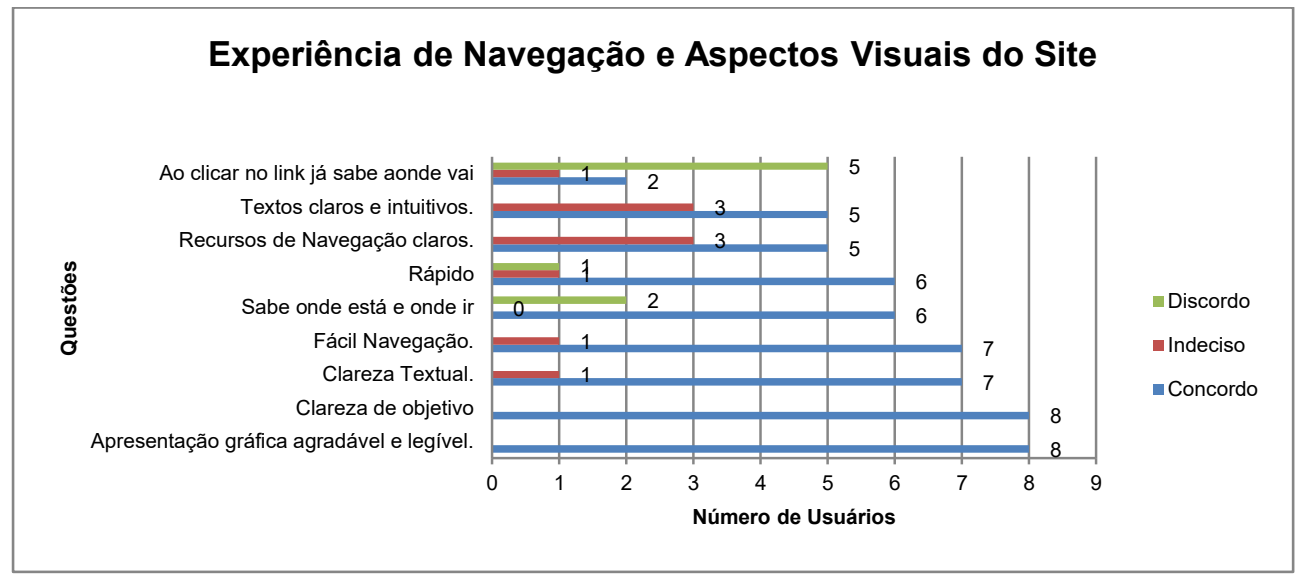

\subsubsection{Procura e produtos}

Quanto a questão de procura e produtos os usuários: três tiveram dificuldades em encontrar no site a opiniões de outros consumidores; cinco encontraram essas informações rapidamente e acharam claras as informações sobre os produtos; seis gostaram dos menus de apresentação dos produtos e das imagens dos produtos apresentados; e, sete conseguiram visualizar rapidamente os dados sobre os produtos, acharam rápida a navegação no site, e que os produtos e serviços estavam expostos de maneira clara e objetiva. Como facilmente observado na figura 8. 
Figura 8 - Opinião dos usuários em relação a sua experiência de procura de produtos no site.

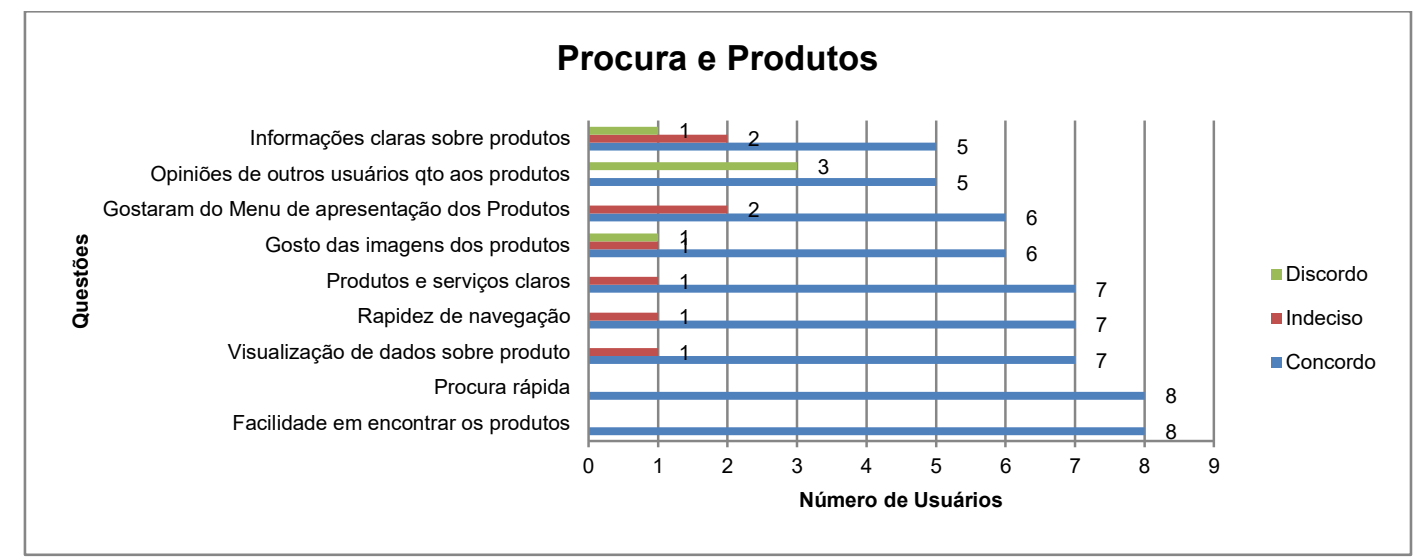

\subsubsection{Processo de Compra}

Quanto ao processo de compra os usuários: Quatro consideraram clara e objetiva a ficha de inscrição e três não concordaram com isso. Três consideraram claras as informações sobre trocas, devoluções e reembolsos, mas três ficaram indecisos quanto a isso. Cinco consideraram o site seguro para compras e que é muito simples o processo de compra no site. Seis disseram: que o site fornece todas as informações necessárias para compra, e informações de entregas, e que consideraram poder abandonar o processo de compra a qualquer momento, que o local de compra é intuitivo e que o processo de compra é muito simples no site. Como observamos na figura 9.

Figura 9 - Opinião dos usuários com relação as informações sobre compras.

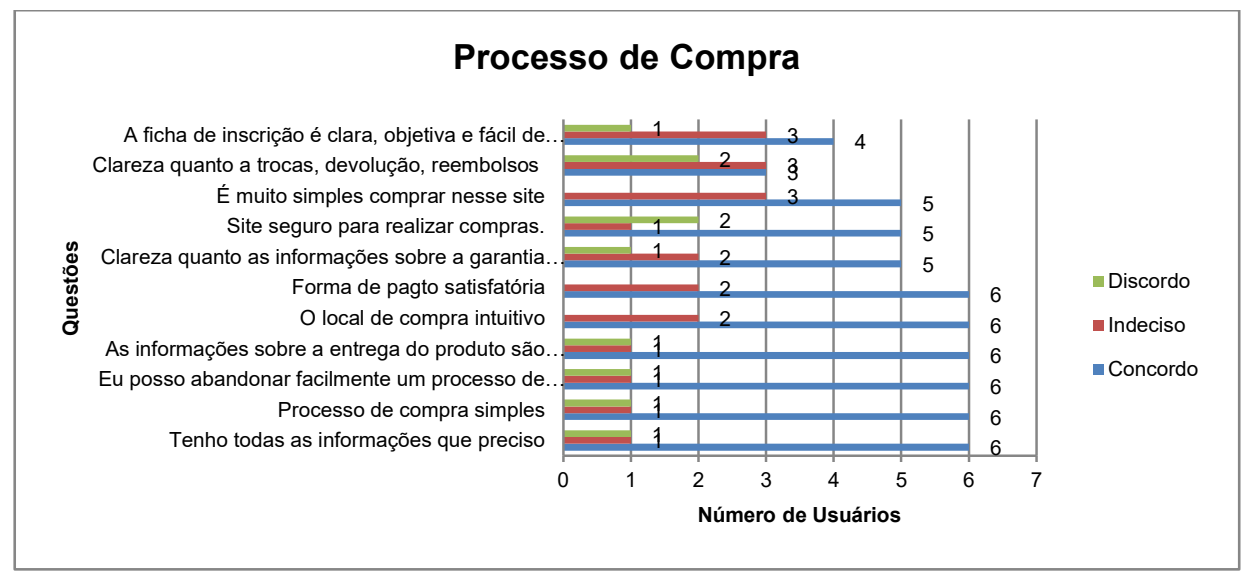

\subsubsection{Serviços Prestados aos clientes, confiança e credibilidade}

Quando questionados quanto aos serviços prestados aos clientes, confiança e credibilidade no site. Três usuários consideraram satisfatório o espaço destinado para comentários e sugestões e três discordam disso. Quatro consideram claras as informações sobre a empresa no site. Quatro usuários concordam que o site é seguro. Cinco usuários 
concordaram que a página de ajuda é clara e seis gostaram do espaço destinado a perguntas frequentes. Como podemos observar na figura 10.

Figura 10 - Opinião dos usuários com relação aos serviços prestados aos clientes, confiança e credibilidade no site da Apple.

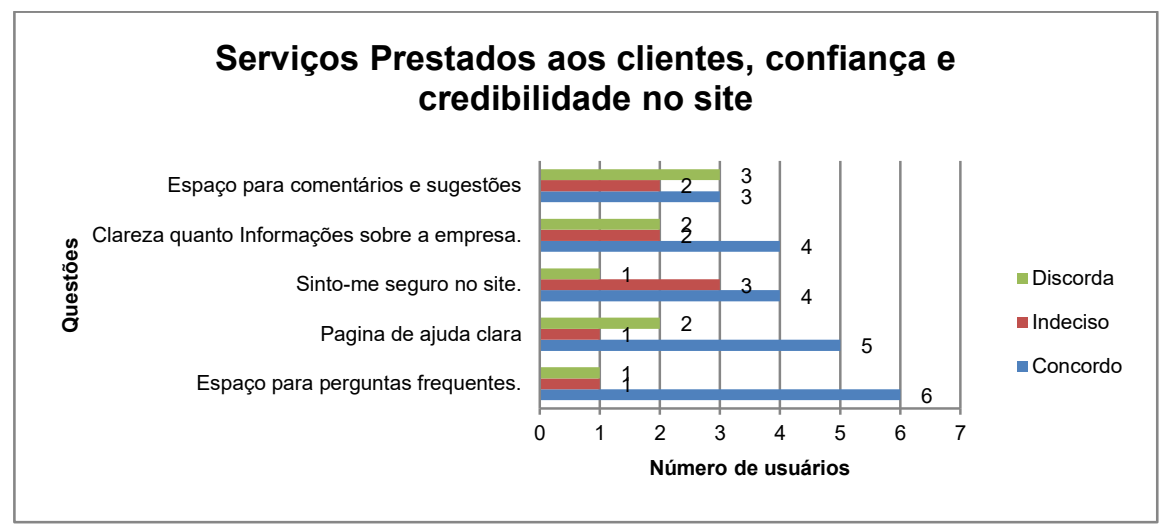

\section{SUGESTÕES DE MELHORIAS}

Como podemos verificar a homepage da Apple não apresenta problemas graves de usabilidade e que é bastante aceita entre os usuários. Então de acordo com os dados levantados no estudo realizado, objetivando melhorar a usabilidade da homepage da Apple e sua interação com os usuários sugere-se o seguinte:

- Que o conteúdo do site seja planejado para envolver mais os usuários e oferecer a oportunidade de ele interagir com comentários e reclamações, sendo assim seria oportuno que a Apple melhore seu formulário de contato e que ele esteja no site em um lugar mais fácil de ser visualizado.

- A Apple deveria estudar a possibilidade de incluir um programa de benefícios e promoções, pois os usuários apontaram durante a entrevista que isso seria um privilégio interessante.

- Os vídeos com a apresentação dos produtos Apple estão na língua inglesa e segundo os usuários deveriam ser dublados ou legendados na língua portuguesa, pois isso foi percebido por eles como desrespeito da Apple ao consumidor brasileiro.

- O Bate papo foi considerado de difícil localização, não sendo muitas vezes percebido pelos usuários, a Apple deveria chamar mais atenção para este serviço e alguns usuários gostariam de ter acesso a um chat que funcione $24 \mathrm{~h}$.

- Deveria ser estudada a possibilidade de uma melhoria nas informações quanto a maiores esclarecimentos quanto ao prazo de entrega dos produtos. Segundo alguns usuários a Apple não respeita o prazo de entrega do seu produto o que causa insatisfações em alguns consumidores.

- Melhoria da qualidade das figuras e palavras utilizadas em seus menus para melhoria do design visual. 
- A empresa deveria observar a dinâmica de leitura da página. Melhorando sua mistura de cores para alguns usuários as cores utilizadas pela Apple deixam a página monótona. A Apple poderia reestudar o assunto.

\section{CONCLUSÃO}

A usabilidade vem recebendo cada dia mais a atenção das empresas, sinônimo de facilidade de uso é utilizada para investigar questões que envolvem navegação e entendimento da interface. Sabemos que uma boa experiência do usuário é fator importante para realização de uma compra on line.

Diante disso, este artigo centrou-se na avaliação de usabilidade da homepage Apple do Brasil. O trabalho teve inicio com uma minuciosa coleta de dados onde buscamos conhecer detalhadamente o site.

Com a análise da usabilidade levando em consideração os princípios de design de interação, diretrizes gerais para o design e diretrizes para o design visual de Leventhal e Barnes, 2008 podemos concluir que por mais que o site da Apple seja considerado por muitos um exemplo de fluidez e clareza das informações ele apresenta alguns problemas de interação que impedem sua boa comunicação com o usuário.

Apesar das falhas encontradas na homepage ela foi considerada, de acordo com a pesquisa com usuários, muito atraente e que oferece seus produtos em destaque facilitando a compra do produto.

Finalizando o estudo podemos concluir que os problemas encontrados no site estudado podem ser facilmente solucionados para adequar a homepage da Apple aos princípios de usabilidade de sistemas para atender as necessidades de interação com os usuários.

\section{REFERÊNCIAS BIBLIOGRÁFICAS}

BARROS, V. T. O.; Avaliação da Interface de um Aplicativo Computacional através de Teste de Usabilidade, Questionário Ergonômico e Análise Gráfica do Design, 2003. Dissertação de mestrado. Programa de Pós-Graduação em Engenharia de Produção da Universidade Federal de Santa Catarina.

CYBIS, J.; PIMENTA, M.; SILVEIRA, M.; GAMEZ, L. Uma Abordagem Ergonômica para o Desenvolvimento de Sistemas Interativos. 1999

CYBIS, W.; BETIOL, A. H.; FAUST, R.; Ergonomia e Usabilidade: Conhecimentos, Técnicas e Aplicações. $2^{\text {a }}$ ed., São Paulo: Novatec Editora, 2010.

EASON K. D. 1984. Towards the experimental study of usability. Behavior and Information Technology, 3(2): 133-143.

FALCÃO, C. S.; SOARES, M. M., Usabilidade de Produtos de Consumo: uma análise dos conceitos, métodos e aplicações. Estudos em Design Revista (online). Rio de Janeiro: v. 21 | n. 2 [2013], p. 01 - 26 | ISSN 1983-196X.

FERREIRA, S B. L.; NUNES, R. R. e-Usabilidade. Rio de Janeiro: LTC, 2008. 
LEVENTHAL, L; BARNES, J.. Usability Engineering: Process, Products and Examples. New Jersey: Pearson Education, Inc. 2008.

MORAES, A. M. Ergonomia: usabilidade de interfaces, interação humano-computador, arquitetura da informação. Anais. $2^{\circ}$ USIHC, Rio de Janeiro: 2003.

MORAES, A.; MONT'ALVÃO, C.. Ergonomia: conceitos e aplicações. 2. ed. Rio de Janeiro. 2AB, 2000.

NIELSEN, Jacob. Usability Engineering. Boston: Academic Press, 1993.

O'BRIEN, J. A. Sistemas de Informação: e as decisões gerenciais na era da Internet. 2. ed. São Paulo: Saraiva, 2004.

PADILHA, A. V., Usabilidade na Web: uma Proposta de Questionário para Avaliação do Grau de Satisfação de Usuários do Comércio Eletrônico. Dissertação apresentada como requisito para a obtenção do grau de Mestre em Ciência da Computação pela UFSC. 2004.

PRATES, R. O. et al. Introdução à Teoria e Prática da Interação Humano Computador fundamentada na Engenharia Semiótica. In: T. Kowaltowski; K. K. Breitman. (Org.). Atualizações em Informática 2007. Porto Alegre: ed. PUC-Rio, 2007, v., p. 263-326.

PRESSMAN, R. S. Engenharia de software. São Paulo: Markron Books, 1995.

SHACKEL, B. . Usability - Context, framework, definition, design and evaluation. 1991

RICHARDSON, S.. Human Factors for Informatics Usability. Cambridge University Press, 21-38.

VELDOF, J. R.; PRASSE, M. J.; MILLS, V, A. Chauffered by the user: usability in the eletronic library. Journal of Library Administration, v. 26, n. 3/4, p. 115-140, 1999. 